\title{
Space weather events in July 1982 and October 2003 and the effects of geomagnetically induced currents on Swedish technical systems
}

\author{
M. Wik ${ }^{1,2}$, R. Pirjola ${ }^{3}$, H. Lundstedt ${ }^{1}$, A. Viljanen ${ }^{3}$, P. Wintoft ${ }^{1}$, and A. Pulkkinen ${ }^{4,5}$ \\ ${ }^{1}$ Swedish Institute of Space Physics, Scheelevägen 17, 22370, Lund, Sweden \\ ${ }^{2}$ Department of Physics, Lund University, P.O. Box 118, 22100 Lund, Sweden \\ ${ }^{3}$ Finnish Meteorological Institute, P.O. Box 503, 00101 Helsinki, Finland \\ ${ }^{4}$ NASA Goddard Space Flight Center, Greenbelt, MD, USA \\ ${ }^{5}$ Goddard Earth Sciences and Technology Center, University of Maryland, Baltimore County, MD, USA
}

Received: 24 April 2008 - Revised: 10 September 2008 - Accepted: 17 November 2008 - Published: 14 April 2009

\begin{abstract}
In this paper, we analyse in detail two famous space weather events; a railway problem on 13-14 July 1982 and a power blackout on 30 October 2003. Both occurred in Sweden during very intensive space weather storms and each of them a few years after the sunspot maximum. This paper provides a description of the conditions on the Sun and in the solar wind leading to the two GIC events on the ground.

By applying modelling techniques introduced and developed in our previous paper, we also calculate the horizontal geoelectric field at the Earth's surface in southern Sweden during the two storms as well as GIC flowing in the southern Swedish $400 \mathrm{kV}$ power grid during the event in October 2003. The results from the calculations agree with all measured data available.

In the July-1982 storm, the geomagnetic field variation, $\Delta B_{x}$, reached values up to $\sim 2500 \mathrm{nT} / \mathrm{min}$ and the geoelectric field reached values in the order of several volts per kilometer. In the October-2003 storm, the geomagnetic field fluctuations were smaller. However, GIC of some hundreds of amperes flowed in the power grid during the October-2003 event. Technological issues related to the railway signalling in July 1982 and to the power network equipment in October 2003 are also discussed.
\end{abstract}

Keywords. Electromagnetics (General or miscellaneous) Geomagnetism and paleomagnetism (Geomagnetic induction) - Solar physics, astrophysics, and astronomy (Flares and mass ejections)

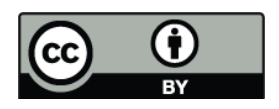

Correspondence to: $\mathrm{M}$. Wik (magnus@lund.irf.se)

\section{Introduction}

"Space Weather" can harmfully affect technological systems in space and at the Earth's surface. The origin of space weather is in the activity of the Sun. A comprehensive understanding of space weather storms and their impacts requires observations and knowledge of the whole chain of phenomena extending from the Sun to the Earth's surface. This is important both scientifically and practically when trying to avoid problems due to space weather.

"Geomagnetically induced currents (GIC)" flowing in networks, such as electric power transmission grids, oil and gas pipelines, telecommunication cables and railway systems, are ground effects of space weather. GIC impacts have already been known for about 150 years (e.g. Boteler et al., 1998; Lanzerotti et al., 1999, and references therein). The flow of GIC can easily be explained based on Faraday's and Ohm's laws: Time-varying currents in the near-Earth space create temporal variations of the geomagnetic field. They induce a (geo)electric field, which drives currents in conductors. Besides technological networks, the Earth is a conductor as well. Currents in the ground also contribute to geomagnetic variations and to induced geoelectric fields occurring at the Earth's surface (e.g. Watermann, 2007).

Electric power transmission systems constitute the most critical technological infrastructures regarding GIC today. Transformers can be saturated due to the flow of a dc-like GIC in the windings possibly leading to problems that may even extend to a collapse of the whole system or to permanent transformer damage (e.g. Kappenman and Albertson, 1990; Kappenman, 1996; Bolduc, 2002; Molinski, 2002, and references therein). Two famous GIC-produced blackouts

Published by Copernicus Publications on behalf of the European Geosciences Union. 
Table 1. Problems due to GIC in ground-based technological systems in Sweden.

\begin{tabular}{|c|c|}
\hline Date & Effects \\
\hline 2 Sep 1859 & $\begin{array}{l}\text { Problems with the telegraph system in } \\
\text { Gothenburg }\end{array}$ \\
\hline 13-15 May 1921 & Fires in telegraph equipment \\
\hline 11 Feb 1958 & $\begin{array}{l}\text { Fires with severe damage in telegraph } \\
\text { equipment }\end{array}$ \\
\hline 13 Nov 1960 & $\begin{array}{l}30 \text { line circuit breakers tripped in the } \\
\text { high-voltage power network }\end{array}$ \\
\hline 13-14 Jul 1982 & $\begin{array}{l}4 \text { transformers and } 15 \text { lines tripped in } \\
\text { the high-voltage power system. Rail- } \\
\text { way traffic lights turned erroneously to } \\
\text { red. Telecommunications were also af- } \\
\text { fected. }\end{array}$ \\
\hline 8-9 Feb 1986 & $\begin{array}{l}5 \text { events in the high-voltage power sys- } \\
\text { tem, } 1-3 \text { lines tripped per event }\end{array}$ \\
\hline 13-14 Mar 1989 & $\begin{array}{l}5130 \mathrm{kV} \text { lines tripped, 5-degree tem- } \\
\text { perature increase in a generator }\end{array}$ \\
\hline 24 Mar 1991 & $9220 \mathrm{kV}$ lines and a transformer tripped \\
\hline 9 Nov 1991 & $\begin{array}{l}\text { One } 220 \mathrm{kV} \text { line tripped. Large pipe-to- } \\
\text { soil voltages in a pipeline }\end{array}$ \\
\hline 1999 & $\begin{array}{l}\text { Radio communication for protection } \\
\text { lost in the power system }\end{array}$ \\
\hline 2000 & Voltage drop in the $400 \mathrm{kV}$ system \\
\hline 6 Apr 2000 & $\begin{array}{l}\text { Largest GIC ever measured in a trans- } \\
\text { former (about } 300 \mathrm{~A} \text { ) }\end{array}$ \\
\hline 30 Oct 2003 & $\begin{array}{l}\text { Power blackout in Malmö, excess heat- } \\
\text { ing in a transformer }\end{array}$ \\
\hline 8 Nov 2004 & $\begin{array}{l}\text { GIC of over } 100 \text { A measured in a trans- } \\
\text { former in southern Sweden }\end{array}$ \\
\hline
\end{tabular}

have occurred, one in Québec, Canada, in March 1989 and the other in southern Sweden in October 2003 during the socalled Halloween storms. They have also been thoroughly analysed and reported (Bolduc, 2002; Pulkkinen et al., 2005; Kappenman, 2005).

Swedish ground-based technological networks have suffered from GIC impacts several times (e.g. Elovaara et al., 1992; Boteler et al., 1998; Lundstedt, 2006). Observed problems are listed in Table 1 (with some minor uncertainties resulting from the lack of precise data). The fact that Sweden has experienced GIC impacts is understandable due to the high-latitude location of the country.

However, the proximity to the auroral zone is not the only criterion for estimating the GIC risk. Both the magnitudes of GIC and the sensitivity of a system to experience problems depend much on the structure, resistances and other technical details of the network and its equipment. Although GIC have possibly affected railway equipment several times in the past, only a few documented and published cases exist in the world. The Swedish railway problem in July 1982 is summarised by Wallerius (1982), and other examples refer to railways in Russia (Belov et al., 2007; Ptitsyna et al., 2007; Kasinskii et al., 2007; Ptitsyna et al., 2008).
The GIC impacts on the southern Swedish power system, resulting in the blackout in Malmö in October 2003, as well as the prevailing space and geophysical conditions then are described by Pulkkinen et al. (2005) and also discussed by Lundstedt (2006). A similar case study of other space weather events was analysed by Lam et al. (2002).

In Sect. 2, we describe the data used for both events in July 1982 and October 2003. This is followed by a description of the conditions on the Sun and in the solar wind leading to the railway signal malfunction in Sect. 3. Geoelectric field calculations are also compared to measured voltages in two communication cables. In Sect. 4, we give a similar description of the conditions on the Sun and in the solar wind leading to the power blackout in Malmö. Additional information is given by estimating values of GIC that flowed in the $400 \mathrm{kV}$ system during the event. Finally, in Sects. 5 and 6 we discuss both events.

\section{Data}

\subsection{Solar data}

Solar data and information were chosen from various sources including Solar-Geophysical Data Prompt Reports and Comprehensive Reports (published by NOAA National Geophysical Data Center, Boulder, USA). Solar images were captured by the solar telescope at the National Astronomical Observatory of Japan. Solar magnetograms were captured by the MDI instrument (Michelson Doppler Imager) onboard the SOHO (Solar Heliospheric Observatory) spacecraft. SOHO is in orbit around the Lagrangian point L1, between the Sun and the Earth, at a distance of about 1.5 million $\mathrm{km}$ from the Earth.

\subsection{Solar wind data}

Solar wind data were measured onboard the IMP8 (Interplanetary Monitoring Platform 8) spacecraft and the ACE (Advanced Composition Explorer) spacecraft. The IMP8 data were collected from the MAG instrument and from the MIT Faraday cup plasma instrument. It consists of the solar wind magnetic $B_{z}$ component, the solar wind density and the speed. The ACE data consist of 4-min averages of the solar wind magnetic $B_{z}$ component and of the absolute magnetic field measurements collected from the MAG instrument, and 1-h average helium ion bulk speed collected from the SWICS instrument. ACE is located in orbit around the L1 point and IMP8 is in an elliptical orbit around the Earth. At midnight on 13-14 July 1982, IMP8 was located at GSM coordinates $(-10,32,-15)$. The ACE/SWEPAM plasma measurements were unavailable during the Halloween events due to contamination. 


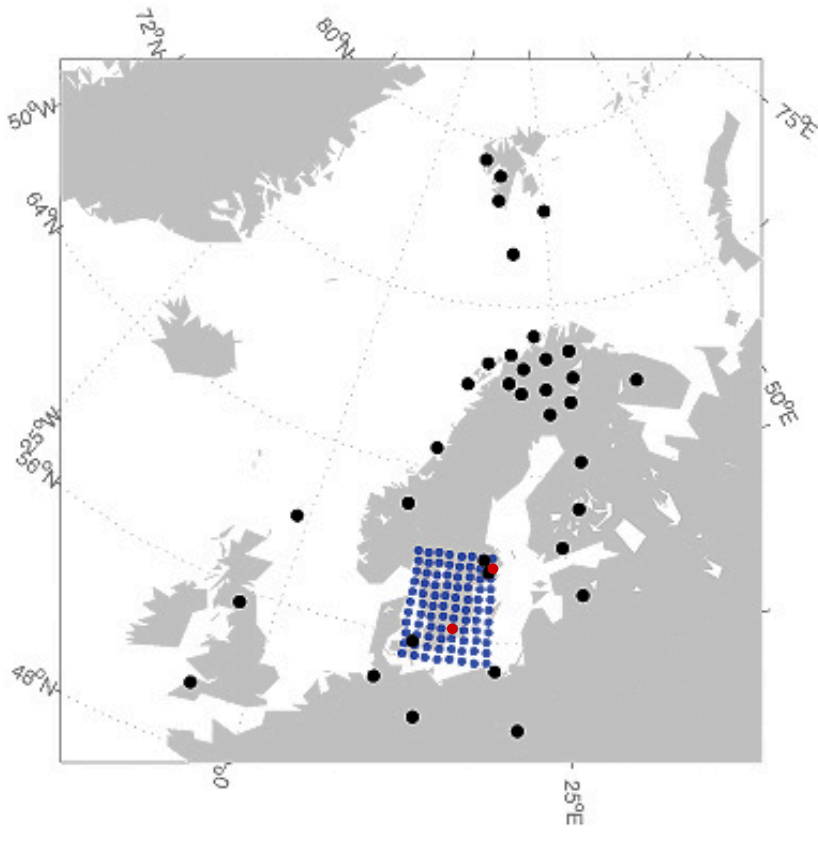

Fig. 1. Magnetometer stations (black) and a dense grid for the interpolation (blue). The observatory in the SW corner of the grid is Brorfelde, and the two observatories in the NE corner of the grid are Lovö and Uppsala. The two grid points, coloured in red, correspond to the locations for which the geoelectric and geomagnetic fields are plotted in Figs. 4, 5, 7 and 8. The more northern is for the July 1982 event, and the more southern is for the October 2003 event.

\subsection{Geomagnetic field data and indices}

Geomagnetic field data, for both events, were collected from several sites in and near southern Sweden. They include data from IMAGE magnetometer array sites and from INTERMAGNET stations. Quiet-day values were subtracted from all data sets. As can be seen in Fig. 1, there are several magnetometers in and around southern Sweden. For the July1982 storm, we, however, used data only from three sites in the vicinity of southern Sweden, i.e. Wingst (Germany), Brorfelde (Denmark) and Lovö (Sweden), whereas for the October-2003 storm, magnetic recordings from altogether 35 stations were applied. This means that the accuracy of the calculations based on ground-based magnetic data is higher for the October-2003 event than for the July-1982 event.

The geomagnetic data, with a 1-min resolution, were interpolated to a dense grid (88 points) covering southern Sweden (see Wik et al., 2008, for further details). From here on, all plots showing interpolated geomagnetic data (as well as geoelectric data) refer to two specific grid points. The first is situated near the city of Stockholm close to the site of voltage recordings in July 1982 (see Sect. 3.2). The second is about halfway between the $400 \mathrm{kV}$ power stations Simpevarp- 1 and Sege (\#20 and \#18 in Fig. 2). These two gridpoints, as well as all other gridpoints, are shown in Fig. 1.

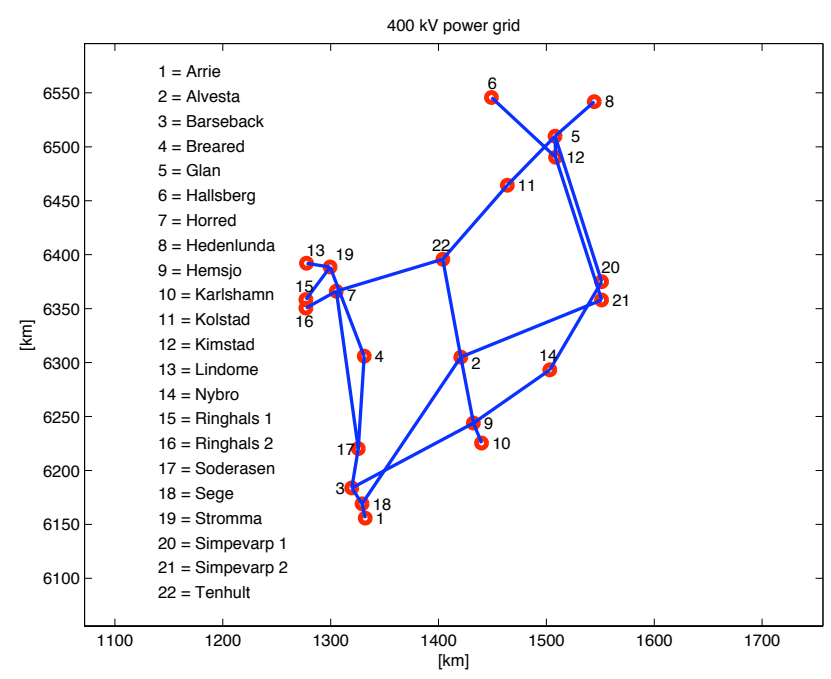

Fig. 2. Southern Swedish $400 \mathrm{kV}$ electric power transmission grid. The transmission lines shown in blue colour are approximated to be straight.

Geomagnetic indices $D_{s t}$ and $K_{p}$ are included as indicators of the global geomagnetic activity. The $K_{p}$ index (Bartels et al., 1939) is obtained from a number of magnetometer stations at mid-latitudes whereas the hourly $D_{s t}$ index (Sugiura, 1964) is obtained from four magnetometer stations located at low latitudes. The $A E$ index, which describes the auroral electrojet, is obtained from a number of stations distributed in the auroral zone in the Northern Hemisphere (Davis and Sugiura, 1966). The $D_{s t}$ and $K_{p}$ indices were collected from the Space Physics Interactive Data Resource (SPIDR) within the NOAA National Geophysical Data Center in Boulder, USA. The $A E$ index was collected from the World Data Center (WDC) for Geomagnetism in Kyoto, Japan.

\subsection{Geoelectric field and voltage data}

The geoelectric field was calculated at the same 88 grid points as the interpolated geomagnetic field. A two-layer Earth conductivity model, derived previously by Wik et al. (2008), was used all over the grid. It consists of a top layer with a thickness of $230 \mathrm{~km}$ and a resistivity of $800 \Omega \mathrm{m}$ above a half-space having a resistivity of $250 \Omega \mathrm{m}$. The surface impedance is the transfer function between horizontal perpendicular magnetic and electric fields in the frequency domain, so that the Fourier-transform of $B_{x}$, multiplied by the surface impedance, and taking the inverse Fourier transform give the geoelectric field $E_{y}$ in the time domain. Here we use the standard orthogonal coordinate system $X Y Z$, where the $x, y$ and $z$ axes point northwards, eastwards and downwards, respectively. 


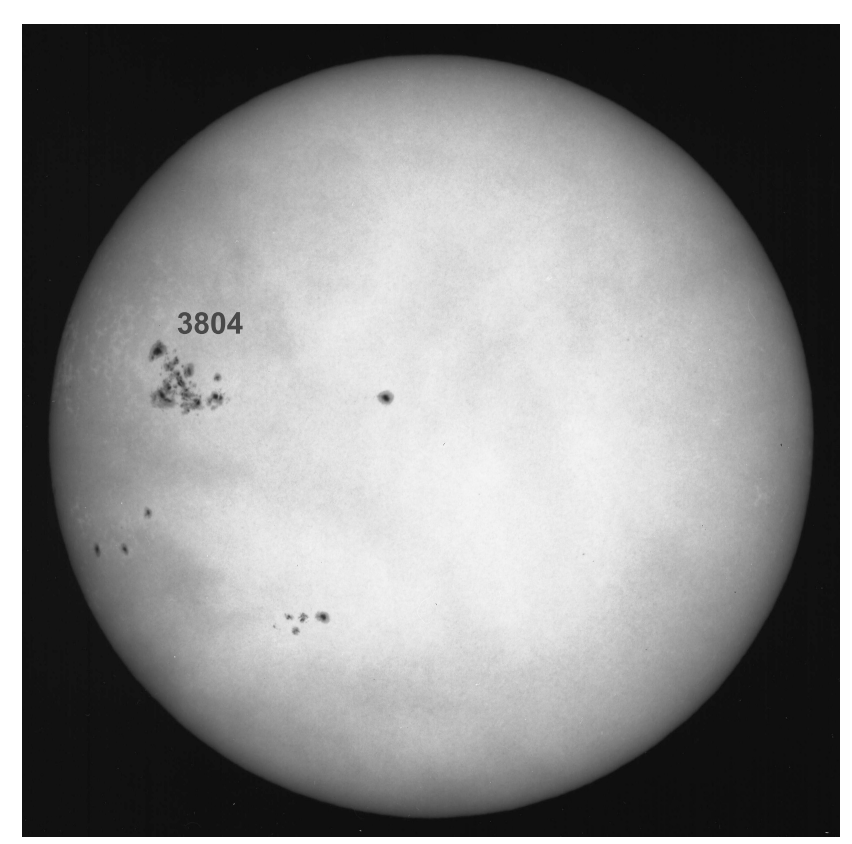

Fig. 3. White-light full disc image of the Sun at 09:18 UT on 12 July 1982 from the National Astronomical Observatory of Japan, Tokyo. The active region 3804, responsible for the geomagnetic storm on 13-14 July 1982, is clearly visible (Courtesy NAOJ).

Voltage data consist of recorded voltages from a southwest-directed telecommunication cable of about $28.7 \mathrm{~km}$ between Stockholm and Södertälje and from a northwest-directed telecommunication cable of about $28.0 \mathrm{~km}$ between Stockholm and Bro. The data consist of chart plots only since digital data are not available.

\subsection{Geomagnetically Induced Currents}

GIC are continuously measured, with a 1-min resolution, at one of the Simpevarp $400 \mathrm{kV}$ transformer neutrals. For the Halloween storms, measured data concern Simpevarp-1 (\#20 in Fig. 2) and are limited to 29 October and the morning of 30 October (see Fig. 8). There are no other measurements due to problems with the monitoring system (private communication with Håkan Swahn). Measured GIC data, during this event, consist of chart plots since digital data are not available.

To calculate GIC in the southern Swedish $400 \mathrm{kV}$ power system, we used a model developed previously by Wik et al. (2008). It consists of the station coordinates and of the network configuration, topology and resistance values, and it has been validated by comparing measured and calculated GIC at Simpevarp-2 (\#21) for many events in 1998 to 2000. GIC were computed for all sites of the $400 \mathrm{kV}$ network using geoelectric data at the grid points. The power grid map in Fig. 2 shows the present network configuration. During
1998 to 2000 the transmission line between Alvesta (\#2) and Hemsjö (\#9) did not exist.

As the power network model only concerns the $400 \mathrm{kV}$ system, the possibility of a GIC flow between the $400 \mathrm{kV}$ and $130 \mathrm{kV}$ systems is only taken into account approximately by decreasing the $400 \mathrm{kV}$ earthing resistance values at stations with autotransformers (Wik et al., 2008). In practice, this means that the calculated GIC flowing between the $400 \mathrm{kV}$ network and the Earth at a station with an autotransformer also includes GIC to (or from) the $130 \mathrm{kV}$ system.

During October 2003, the power grid configuration was exceptional and slightly different from that shown in Fig. 2 since Simpevarp-2 (\#21) was not used at all and the lines from Alvesta (\#2) and Kimstad (\#12) were connected to Simpevarp-1 (\#20).

\section{The event of July 1982}

\subsection{Conditions on the Sun and in the solar wind}

The July-1982 event started with a proton event registered at 07:00 UT on 11 July. It reached its maximum on 13 July at 16:15 UT with a proton flux of $2900 \mathrm{pfu}$. This is an indication of a CME approaching and, possibly, a geomagnetic storm (Gleisner and Watermann, 2006). The CME was perhaps related to a disappearing filament, from region 3804 located close to the solar equator but about 20-40 degrees east of the central meridian. The active region is shown in Fig. 3 where east is to the left. A flare was also observed beginning at 05:03 UT on 12 July and ending at 06:30 UT the same day. The July-1982 event is also described by e.g. Mavromichalaki et al. (1991) and by Stüdemann et al. (1986).

The solar wind magnetic field, density and speed are shown in Fig. 4. The solar wind magnetic field component $B_{z}$ was moderate until about 17:00-18:00 UT, on 13 July, when large negative values were detected. Later, at about 00:30 UT on 14 July, after a period of missing data, the instrument again detected large values, close to $-40 \mathrm{nT}$, increasing to positive values. We believe that a CME, which arrived sometime after 16:00 UT on 13 July, was the cause. There is a large gap of missing data for the solar wind density and speed until about 04:00 UT on 14 July when high values were detected. This is also an indication of a CME.

\subsection{Ground-based geomagnetic and geoelectric fields}

The horizontal magnetic variations close to Stockholm, as indicated by the more northern red grid point in Fig. 1, are shown in Fig. 4. Since the rate-of-change of the horizontal geomagnetic field, $d B / d t$, is related to the electric field it is also useful to examine the time derivatives of $B_{x}$ and $B_{y}$. Here we simply use $\Delta B=B(t+1)-B(t)$ as an approximation for $d B / d t$.

The geomagnetic storm on 13 July 1982, reached a peak intensity in $\Delta B_{x}$ of more than $2500 \mathrm{nT} / \mathrm{min}$ at midnight when 


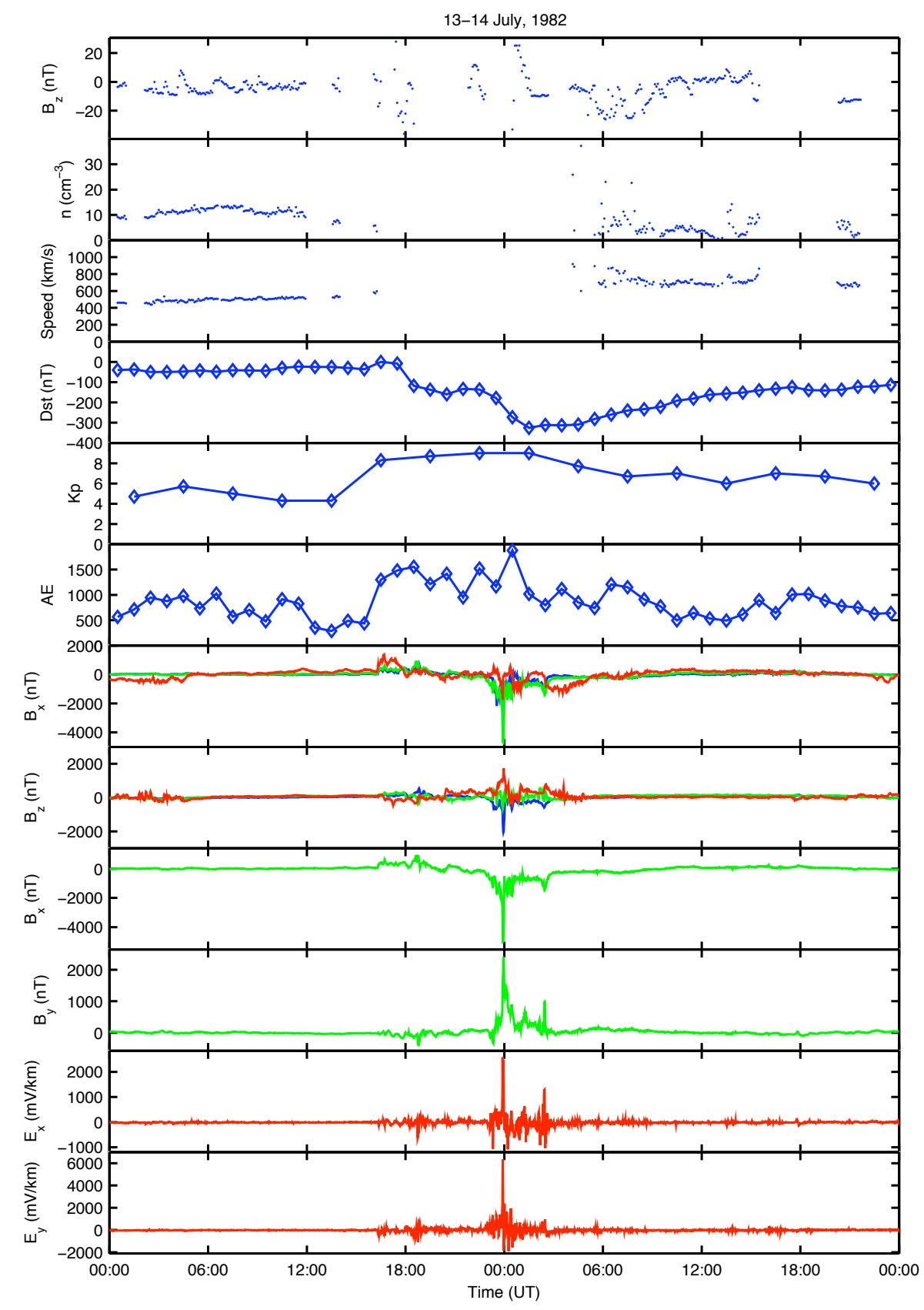

Fig. 4. Stack plot of IMP8 solar wind data, geomagnetic indices, geomagnetic data and geoelectric data for 13-14 July 1982. The IMP8 data, in the top three panels, include the solar wind magnetic field component $B_{z}$, the solar wind density, and the speed. The following panels show the geomagnetic indices $D_{s t}, K_{p}$ and $A E$. Measured geomagnetic components, $B_{x}$ and $B_{z}$, are shown for Brorfelde (blue), Lovö (green) and Sodankylä (red). Interpolated geomagnetic north $B_{x}$ and east $B_{y}$ components are shown next. These data refer to the more northern red grid point in Fig. 1 (see additional details in the text). Below the geomagnetic data are the calculated geoelectric north $E_{x}$ and east $E_{y}$ components at the same point.

the north component $B_{x}$ was reduced by almost $-5000 \mathrm{nT}$ around midnight. The simultaneous peak intensity in $\Delta B_{y}$ was about $700 \mathrm{nT} / \mathrm{min}$. This should be compared to the largest value at Nurmijärvi, in southern Finland, observed the same day, when $\Delta B_{x}$ reached $40 \mathrm{nT} / \mathrm{s}$ (Viljanen, 1997). During the blackout in Québec, Canada, in March 1989, the geomagnetic storm reached an intensity of $\sim 480 \mathrm{nT} / \mathrm{min}$ (Kappenman, 2006). 


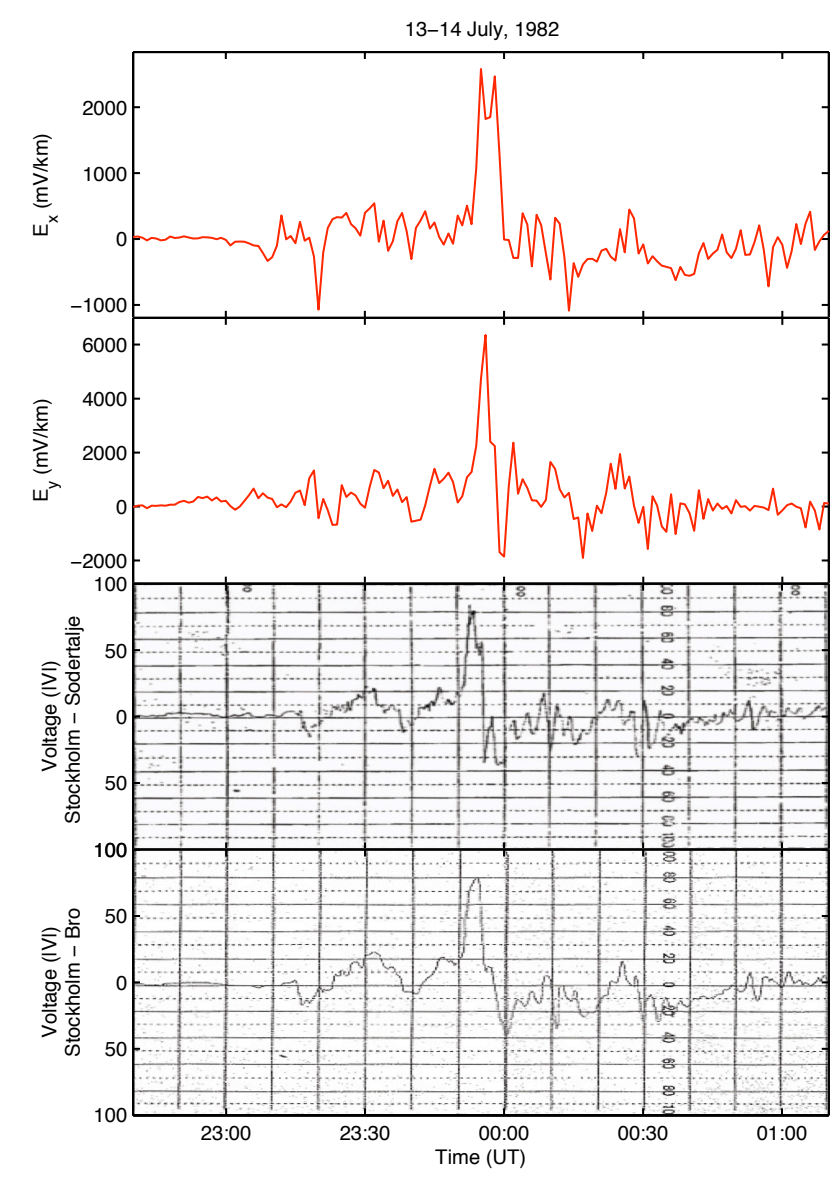

Fig. 5. Two voltage recordings (lower panels), together with electric field calculations (upper panels), from 22:40 UT on 13 July to $01: 10$ UT on 14 July 1982 . The first recording is from an approximately southwest-directed telecommunication cable of about $28.7 \mathrm{~km}$ between Stockholm and Södertälje. The second recording is from an approximately northwest-directed telecommunication cable of about $28.0 \mathrm{~km}$ between Stockholm and Bro. The calculated electric field data refer to the more northern red grid point in Fig. 1.

At around 16:00 UT on 13 July the shock front from the CME arrived causing a sudden storm commencement (SSC) and the compression of the magnetosphere on the dayside (see Mavromichalaki et al., 1991; Stüdemann et al., 1986). After 18:00 UT the $D_{s t}$ index decreased to negative values indicating the injection of particles into the equatorial ring current. The main phase reached $D_{s t}=-325 \mathrm{nT}$. The $K_{p}$ index reached values of 8 to 9 until the early hours next day. The $A E$ index reached values up to almost $2000 \mathrm{nT}$, indicating an increased activity of the electrojets corresponding to negative values in the solar wind $B_{z}$ component (e.g. Davis and Sugiura, 1966). Since the electrojets were occasionally located at very southern latitudes, the $A E$ stations did not properly observe them. This is the reason why $A E$ can be much smaller than the ground-based $B_{x}$ value at subauroral sites.
In 1982 the magnetometer network was sparse. However, we can qualitatively estimate the location of the westward electrojet. The negative variation of $B_{x}$ around the midnight of 13-14 July was $\sim 5000 \mathrm{nT}$ at Lovö and $\sim 4000 \mathrm{nT}$ at Brorfelde, whereas at Sodankylä (lat 67.37 N) it was "only" $\sim 2000 \mathrm{nT}$. This suggests that the location of the centre of the electrojet was obviously near and a little south of the latitude of Lovö (see the middle panels in Fig. 4). Using data from only these three observatories does not enable a more precise determination of the position of the electrojet (see e.g. Maurer and Theile, 1978; Bolduc et al., 1998, 2000).

Two voltage recordings, together with electric field calculations (i.e. at the more northern red grid point in Fig. 1), around midnight on 13-14 July 1982 are shown in Fig. 5. The first voltage recording is from an approximately southwest-directed telecommunication cable, from Stockholm to Södertälje, with a length of about $28.7 \mathrm{~km}$. The second voltage recording is from an approximately northwestdirected cable, from Stockholm to Bro, with a length of about $28.0 \mathrm{~km}$. These cables belonged to the Swedish railway system [private communication with Bertil Artelius]. The peak value, for both recordings, roughly $80 \mathrm{~V}$ thus means horizontal geoelectric components of about $3 \mathrm{~V} / \mathrm{km}$, so that the total geoelectric field, having an east-west direction, reached a value of approximately $4-5 \mathrm{~V} / \mathrm{km}$. This event is also described by Kappenman (2006), who refers to a geoelectric field magnitude of $9.1 \mathrm{~V} / \mathrm{km}$. However, the value represents a very local electric field because it is based on a recording with the line length of only $0.921 \mathrm{~km}$ [private communication with Bertil Artelius]. Thus our data based on the Stockholm-Södertälje and Stockholm-Bro measurements are more representative in the evaluation of space weather impacts on large-scale networks.

\subsection{Railway effects}

A description of the technological impact that resulted in a traffic light problem on the Swedish railways on 1314 July 1982 is provided by Wallerius (1982). Supplemented by additional information (private communication with B. Artelius), the event is summarised in this section.

In the night between 13 and 14 July 1982, the traffic lights turned red without any obvious reason in a railway section of about $45 \mathrm{~km}$ in length in the southern part of Sweden (a little north of the centre of the grid shown in Fig. 1). After a while the lights turned green and back to red again later. The reason was that the geoelectric field affected the relays as follows.

In normal conditions, in the absence of a train, a battery maintains a de voltage of 3 to $5 \mathrm{~V}$ between the rails and over a relay, which is thus energised. A second circuit affected by the relay is connected to the traffic lights, which implies that the light is green when the relay is energised, whereas a deenergised relay produces a red light. When a train is present, 


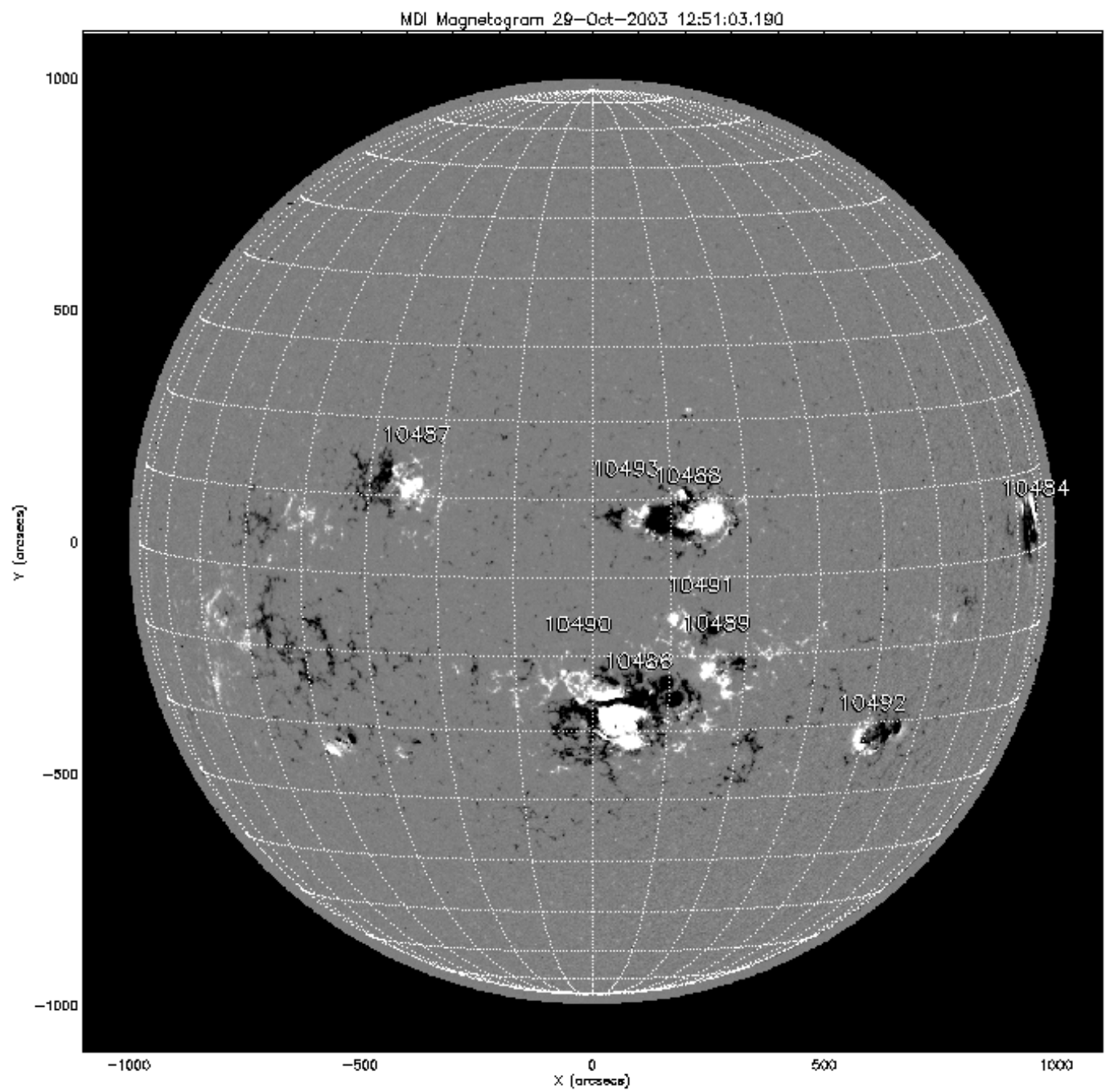

Fig. 6. Magnetogram showing the solar magnetic field on 28 October 2003, at about 12:51 UT. The huge active region 486, responsible for the space weather event resulting in the blackout in Malmö, is located in the middle just south of the solar equator (Courtesy MDI/SOHO team).

the axles of the train short-circuit the rails making the voltage zero thus de-energising the relay leading to a red light.

During this event, the voltage between the rails associated with the induced geoelectric field had magnitudes in the order of volts. Consequently, it was large enough to affect the above-mentioned voltage of 3-5 V. At times when the induced voltage was opposite to the battery voltage, the latter was cancelled (at least partly) resulting in a de-energisation of the relay, which thus reacted as if the rails were occupied and caused the traffic lights to turn red. When the induced voltage was reversed the lights became green again.

Geoelectric field values of about 4-5 V/km were observed in Sweden during the July-1982 storm (Sect. 3.2), which means that voltages of about $3-5 \mathrm{~V}$ are already obtained at length scales of one to two kilometres or even less, which can explain the railway traffic light malfunction. In the absence of an accurate technical description and diagram of the operation of the battery, the relay and the associated circuits, a detailed model calculation of the induced voltages in the equipment is neglected in this paper.

\section{The event of October 2003}

\subsection{Conditions on the Sun and in the solar wind}

Around 18 October 2003, the Sun showed signs of unusually high activity with the emergence of the active region 484 . On 22 October, the large and complex active region 486 appeared on the east limb. During the period 26 October to 5 
November a total of five full halo-CMEs arrived at the Earth with two of them producing geomagnetic storms with $K_{p}=9$. The active region 486 was responsible for both of them (see e.g. Weaver et al., 2004, and references therein). The active region 486 is shown in Fig. 6. From here on we focus mainly on the time period from 28 to 30 October.

The Sun-Earth events of October 2003, whose solar and solar wind characteristics are depicted by the stackplot in Fig. 7, began on 28 October at 11:10 UT with an X17 flare from the region 486 . This was followed by a proton event at around 12:00 UT reaching the maximum of $29500 \mathrm{pfu}$ at around 06:15 UT on the following day, when a CME driven shock arrived at L1. The halo-CME, from the region 486 located almost at the centre of the solar disc, had a speed close to $2000 \mathrm{~km} / \mathrm{s}$. At the same time the magnetic field magnitude $|\boldsymbol{B}|$ increased to about $60 \mathrm{nT}$ and the $B_{z}$ component reached about $-50 \mathrm{nT}$. The propagation time for this CME was around $19 \mathrm{~h}$. The $B_{z}$ component then turned northwards until $\sim 18: 00 \mathrm{UT}$ when it rotated southwards to negative values of about $-25 \mathrm{nT}$. It then stayed negative until about 02:40 UT on 30 October.

On 29 October at 20:49 UT an X10 flare event was observed, perhaps associated with the second halo-CME, with a speed $\sim 2000 \mathrm{~km} / \mathrm{s}$. The travel time for this CME was about the same and it reached the Earth on 30 October around 16:20 UT. A shock was then observed, as indicated by the rapid increase in $|\boldsymbol{B}|$. At around 18:20 UT the $B_{z}$ component turned southwards, reaching $-35 \mathrm{nT}$, until it turned northwards again after midnight (Skoug et al., 2004; Zurbuchen et al., 2004).

On 4 November, when the active region 486 had reached the western limb of the Sun, it produced an X28 flare (the largest ever recorded) and a CME moving outward with a speed above $2300 \mathrm{~km} / \mathrm{s}$. However, this time the CME headed in a direction almost perpendicular to the Sun-Earth direction leading to only a minor geomagnetic storm.

\subsection{Ground-based geomagnetic and geoelectric fields}

The interpolated horizontal geomagnetic and calculated horizontal geoelectric fields are shown in Figs. 7 and 8 during the storm events on 29-30 October 2003. The fields presented concern the more southern red grid point shown in Fig. 1 located approximately halfway between Sege and Simpevarp (\#18, \#20 and \#21 in Fig. 2).

At 06:15 UT on 29 October, a geomagnetic disturbance first occurred due to the solar wind shock, as seen in Figs. 7 and 8 . The geomagnetic field was highly disturbed until $\sim 07: 00$ UT when the solar wind magnetic field component $B_{z}$ turned positive. At around 19:00 UT the geomagnetic disturbance again increased. This lasted until $\sim$ 03:00 UT on 30 October.

With the arrival of a second CME on 30 October, another geomagnetic storm began in the evening. The highest intensity of $\Delta B_{x}$ was around $400 \mathrm{nT} / \mathrm{min}$ at 20:04 UT and the geomagnetic field deviated up to $\sim 2000 \mathrm{nT}$ from the quiet day values. The electric field reached the value of $2 \mathrm{~V} / \mathrm{km}$ at $\sim 20: 04$ UT. At this point scientists of IRF in Lund were already in contact with the operators of the E.ON power company to give them the latest update about the geomagnetic storm. Despite this, a blackout occurred at 20:07 UT in the city of Malmö. High intensity levels of $\Delta B_{x}$ around $350 \mathrm{nT} / \mathrm{min}$ also occurred at 20:25 UT and 21:18 UT. The highest intensity of $\Delta B_{y}$, with values of $-470 \mathrm{nT} / \mathrm{min}$ and $573 \mathrm{nT} / \mathrm{min}$, occurred on 29 October at around 06:45 UT and 15:00 UT. High values of about $400 \mathrm{nT} / \mathrm{min}$ also occurred on 30 October at $\sim 21: 30$ UT.

The first CME resulted in an extreme geomagnetic storm, with $K_{p}=9$. The geomagnetic storm intensity stayed at levels above $K_{p}=7$, even when the solar wind $B_{z}$ component was positive, until the morning of 30 October. The second CME also resulted in an extreme storm, with $K_{p}=9$, on 30 October (see Fig. 7). The $A E$ index reached high values when the solar wind $B_{z}$ component reached high negative values. This corresponds to the southward movement and enhancement of the auroral oval.

The $D_{s t}$ index indicates that the equatorial ring current evolved during the event starting with the initial phase at around 06:15 UT and reached a minimum at midnight. The recovery phase continued until about 18:00 UT on 30 October when the second geomagnetic storm began.

To determine the location of the electrojet we used the method of spherical elementary current systems (SECS; Amm and Viljanen, 1999). We calculated the equivalent current density at the ionospheric altitude of $100 \mathrm{~km}$ along the meridian $22.06^{\circ} \mathrm{E}$ at the latitude range $59.02-79.42^{\circ} \mathrm{N}$ with a 0.6 degree step. The centre of the eastward electrojet is at the latitude of the maximum eastward current density, and the westward electrojet is centred at the minimum. The result is shown in the middle panels in Fig. 7.

\subsection{Calculation of GIC causing the Malmö Blackout}

The power blackout that occurred in the city of Malmö in southern Sweden on 30 October 2003, began at 20:07 UT and lasted for 20 to $50 \mathrm{~min}$ affecting about 50000 customers (analysed in detail by Pulkkinen et al., 2005). The blackout was caused by the tripping of a $130 \mathrm{kV}$ line. It resulted from the operation of a relay that had a higher sensitivity to the third harmonic $(=150 \mathrm{~Hz})$ than to the fundamental frequency $(=50 \mathrm{~Hz})$. The excessive amount of the third harmonics in the system has been concluded to have resulted from transformer saturation caused by GIC.

Regarding the blackout in Malmö, GIC values at the nearby station Sege (\#18) are of particular interest. However, as harmonics can propagate all over the network, large GIC in other transformers have probably also contributed to the adverse effects resulting in the blackout. Therefore we also consider GIC at Arrie (\#1) and Barsebäck (\#3) located next to Sege, and at Simpevarp-1 (\#20). Calculated GIC 


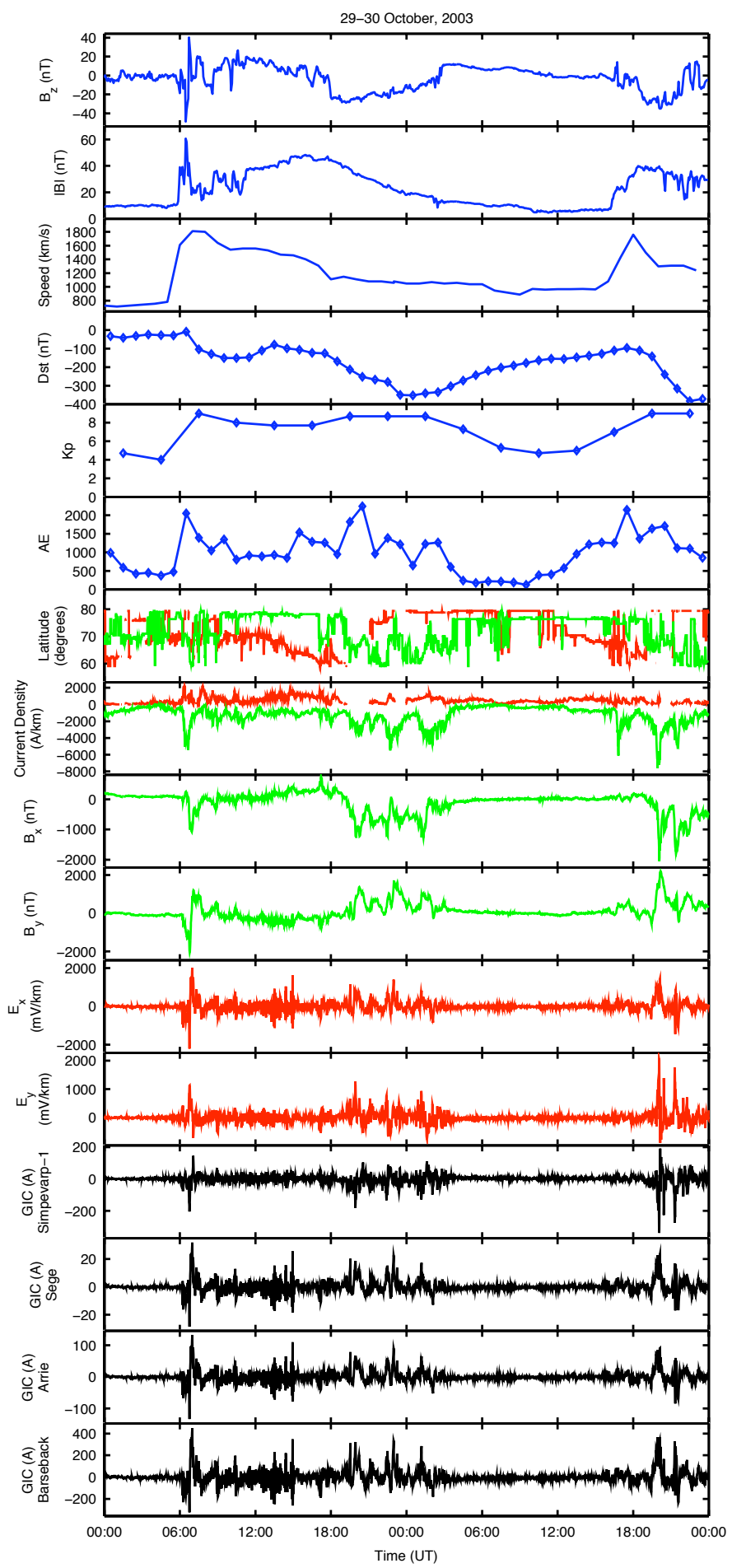

Fig. 7. Stack plot of ACE solar wind data, geomagnetic indices, electrojet parameters, horizontal geomagnetic and geoelectric data and geomagnetically induced currents for 29-30 October, 2003. The three top panels show the solar wind $B_{z}$ component and magnetic field magnitude $|\boldsymbol{B}|$ from ACE/MAG and the helium ion bulk speed from ACE/SWICS. The next three panels present the $D_{s t}, K_{p}$ and $A E$ indices. The calculated latitude and intensity for the eastward (red) and westward (green) electrojets are shown in the next two panels. Interpolated geomagnetic and calculated geoelectric data depicted in the following four panels refer to the more southern red grid point in Fig. 1. The four bottom panels present calculated GIC at Simpevarp-1, Sege, Arrie and Barsebäck (stations \# 20, \# 18, \# 1 and \# 3 in Fig. 2). 


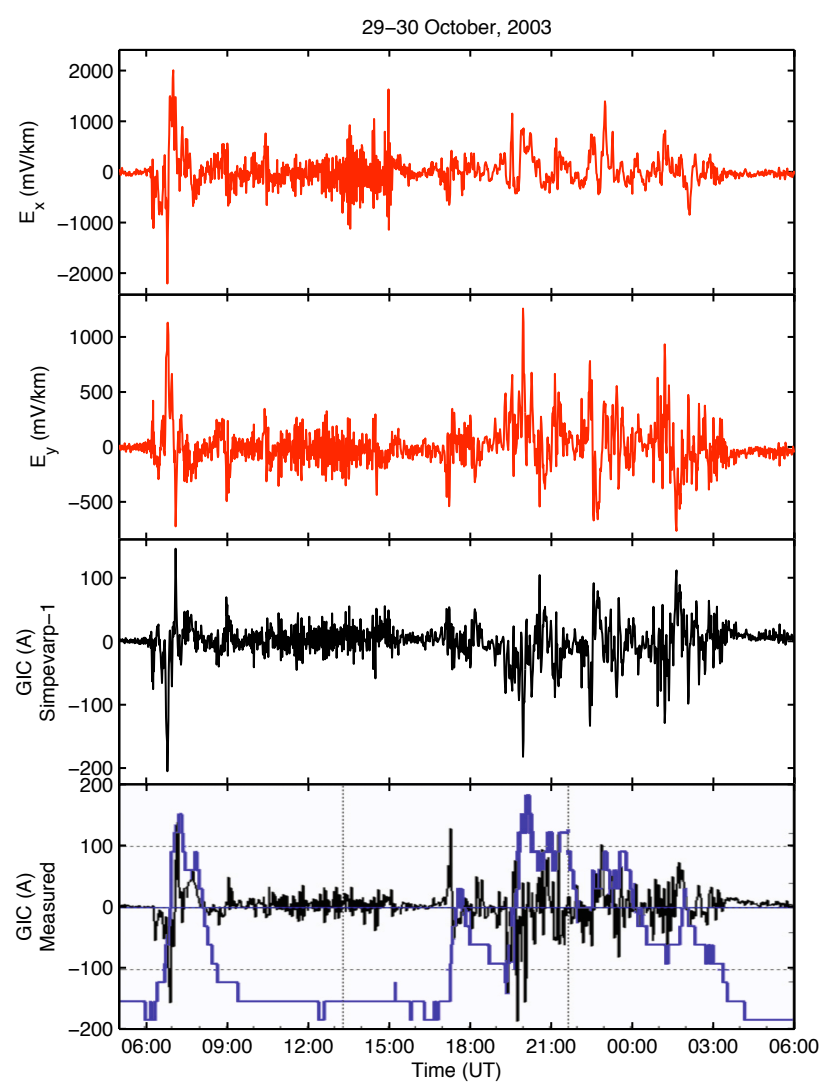

Fig. 8. The bottom panel shows measured GIC (black curve) and transformer temperature (blue curve) at Simpevarp-1 (\#20 in Fig. 2) from 05:00 UT on 29 October to 06:00 UT on 30 October 2003. The total range from bottom to top in the figure for the temperature is roughly ten degrees. There are no measurements at later times on 30 October due to a problem with the monitoring system (private communication with H. Swahn). The second panel from the bottom presents calculated GIC at Simpevarp-1. The two upper panels refer to the calculated geoelectric field at the more southern red grid point in Fig. 1.

for these four $400 \mathrm{kV}$ stations on 29 and 30 October 2003, are depicted in Fig. 7. A shorter interval of the calculated Simpevarp-1 GIC curve is also shown in Fig. 8, which indicates a good agreement between measured and calculated GIC. Unfortunately, there are no measured GIC data available for Simpevarp-1 at times later than 06:00 UT on 30 October.

The GIC magnitudes remain clearly smaller at Sege than at the three other sites, the reason for which is an additional resistor of a few ohms in the earthing lead of the $400 \mathrm{kV}$ transformer neutral at Sege that efficiently reduces GIC. The calculated GIC at Simpevarp-1 reaches a peak value of about $330 \mathrm{~A}$ a few minutes before the time of the Malmö blackout (at 20:07 UT on 30 October). The simultaneous GIC values at Arrie and Barsebäck are about $90 \mathrm{~A}$ and around $300 \mathrm{~A}$.
Calculated GIC data at Sege exhibit small values, around 15 to $20 \mathrm{~A}$, at the time of the blackout although the highest GIC already occurred there in the morning of 29 October.

\section{Discussion}

In the July-1982 storm, the largest time derivative values of the ground magnetic field were much stronger than in the October-2003 storm. A similar conclusion was also made by Kappenman (2005). The peak value of about $2500 \mathrm{nT} / \mathrm{min}$ obtained for the July-1982 event is in agreement with the value of $40 \mathrm{nT} / \mathrm{s}$ in southern Finland reported by Viljanen (1997). We also see that, though being very large, the geoelectric field values remained smaller in the Halloween storm than in the July-1982 event.

Unfortunately there are large gaps in the solar wind data for the midnight hours on 13-14 July 1982. However, a large increase in the solar wind density and speed did occur in the afternoon of 13 July (Stüdemann et al., 1986). On 22 July there was a second proton event, from the same region, but now 86 degrees west of the central meridian. This time the CME did not cause a significant disturbance, possibly because only the flank of the CME arrived at the Earth.

During 29-30 October 2003 there were two CMEs, resulting in intense geomagnetic disturbances. It is possible that these two CMEs, in combination, were the cause of higher geomagnetic disturbances on 30 October. An X28 flare was observed at 19:50 UT on 4 November together with the fastest CME ( $\sim 2700 \mathrm{~km} / \mathrm{s})$ during October-November 2003 (Gopalswamy et al., 2005). This time, however, the CME was not geoeffective since it erupted near the west limb of the Sun.

For the July-1982 event, we considered the geoelectric field affecting the railway circuit. We calculated the geoelectric field based on geomagnetic data and a two-layer Earth model and compared with voltage recordings from two telecommunication cables in Sweden. However, we have to take into account that the derivation of the geoelectric field from the chart plots of the voltage recordings is not completely reliable because we do not have exact documents of the recording arrangements in July 1982 including the distances between the measurement electrodes in the ground. This question is related to the fact that, due to the nonconservative, i.e. rotational, nature of the geoelectric field the cable applied to the recording should be straight (see GomezTrevino, 1987). A more quantitative calculation including an exact description of the railway circuit belongs to the aims of our future studies.

The calculated geoelectric field values of several volts per kilometre are much larger than the magnitudes calculated by using geomagnetic recordings from the Nurmijärvi Observatory in southern Finland (Pirjola, 1985). An obvious reason is that the uniform-Earth assumption made in those calculations is too rough, which emphasises the importance of an 
appropriate choice of the ground conductivity model in computations of the geoelectric field and GIC.

The calculated geoelectric field gets higher values than those based on the voltage recordings. A possible reason for this discrepancy is in the use of the two-layer ground conductivity model described in Sect. 2.4 for the area where the voltage measurements were carried out since the model was derived by comparing calculated and measured GIC data at Simpevarp-2 (\#21 in Fig. 1) located further south (Wik et al., 2008).

The July-1982 storm also caused GIC problems in the Swedish high-voltage power system by tripping four highvoltage transformers and fifteen lines (Table 1). Fortunately, however, this happened in a favourable load situation, obviously thanks to the summer night time, and consequently more serious consequences were avoided. The same storm affected the telecommunication system in Sweden as well (Table 1). A lightning protection device was burnt at a station, and at other stations alarms were activated (Wallerius, 1982).

During the October-2003 event, particularly large GIC values could be expected at Simpevarp-1, as it was a corner and end station of altogether four lines. Normally Simpevarp-1 is connected to two stations only (see Fig. 2).

The Malmö blackout was definitely caused by the misoperation of a relay too sensitive to the third harmonics of the fundamental frequency of $50 \mathrm{~Hz}$. Since the southern Swedish $130 \mathrm{kV}$ network is connected to the $400 \mathrm{kV}$ system, GIC can easily flow between the two networks. In general, a higher voltage level with smaller resistances of the transmission lines means larger GIC values. Thus, GIC in the southern Swedish $400 \mathrm{kV}$ system played a major role for the blackout in Malmö.

Consequently, there is a good reason to compute GIC in the $400 \mathrm{kV}$ system for the October-2003 event. It is worth emphasising that the geoelectric data shown in Figs. 7 and 8 refer to a particular grid point indicated in Fig. 1 and chosen to be representative for both Malmö/Sege and the GIC recording site at Simpevarp when situated about halfway between them. However, in the calculation of GIC, the spatial variation of the geoelectric field across southern Sweden was taken into account exactly. The calculated GIC values, which extend to a couple of hundreds of amperes, also indicate the intensity of the Halloween storm and provide further evidence that GIC were really the cause of the blackout. In order to evaluate reasons for the blackout, Pulkkinen et al. (2005) also present simulated GIC data for the Halloween storm, and the values obtained extend to hundreds of amperes. However, their power grid model is quite crude as they only consider a single line segment of $100 \mathrm{~km}$ in length. Even such a simple model can describe GIC qualitatively but a quantitative estimation requires a full modelling of the real power grid as is done in this paper.

\section{Conclusions}

The purpose of this study is to describe the two GIC events that occurred in Sweden during 13-14 July 1982 and 29-30 October 2003, both of which occurred a few years after the sunspot maximum.

In the first event, a solar flare was observed on 12 July, perhaps related to a CME from region 3804. The shock arrived at the Earth around 16:00 UT on 13 July causing an SSC. The $D_{s t}$ index decreased to $-325 \mathrm{nT}$ and the $K_{p}$ index reached values of 8 to 9 until the early hours next day, on 14 July.

In Sweden, close to Stockholm, the geomagnetic disturbance reached a maximum intensity around midnight when the north component $B_{x}$ decreased by almost $5000 \mathrm{nT}$ in a few minutes. The calculated electric field reached a maximum of around 3 and $6 \mathrm{~V} / \mathrm{km}$, for the $E_{x}$ and $E_{y}$ components. This was large enough to disturb the usual voltage of 3 to $5 \mathrm{~V}$ between the rails and over a relay and thus cause a malfunction of the railway signal system.

The second event, in October 2003, started with an X17 flare from the region 486 at 11:10 UT on 28 October. At 06:15 UT, on the following day, a halo-CME driven shock arrived at $\mathrm{L} 1$. This resulted in an extreme geomagnetic storm, with $K_{p}=9$ and $D_{s t}=-353 \mathrm{nT}$. In southern Sweden, the peak geomagnetic disturbance occurred at around 06:45 UT with $B_{y}=\sim-2000 \mathrm{nT}$.

At 20:49 UT, on 29 October, a new flare, an X10, was observed. The second halo-CME caused an SSC at 16:20 UT on 30 October. The result was another extreme storm, with $K_{p}=9$ and $D_{s t}=-383 \mathrm{nT}$. This caused a peak total geomagnetic disturbance of about $2000 \mathrm{nT}$ and a geoelectric field of about $2 \mathrm{~V} / \mathrm{km}$ at 20:04 UT. The blackout in the city of Malmö occurred at 20:07 UT and lasted for 20 to $50 \mathrm{~min}$ affecting about 50000 customers. The cause was a relay too sensitive to the third harmonics of the fundamental frequency. These harmonics were a result from transformer saturation due to GIC. Another peak, in the geomagnetic field, occurred at $\sim$ 21:20 UT, without any reported problems.

Acknowledgements. We thank Sture Lindahl (Gothia Power AB, Gothenburg, and Lund University, Sweden) and Håkan Swahn (E.ON, Sweden) for many useful discussions on GIC effects on power systems. Håkan Swahn is also acknowledged for providing measured GIC data and other important information about the Halloween storm.

We also thank Bertil Artelius (Banverket, Swedish Rail Administration) for providing us with technical information about GIC impacts on the Swedish railways and about geoelectric recordings in Sweden.

We are grateful to E.ON and Svenska Kraftnät (SVK, Sweden) for providing power grid data to us and for supporting us otherwise. We also thank all institutes providing magnetometer data to IMAGE and INTERMAGNET. We wish to thank Lasse Häkkinen (FMI, Finland) for helping us in collecting magnetic data used in the study.

We thank the NOAA National Geophysical Data Center in Boulder, USA, and the World Data Center (WDC) for Geomagnetism in 
Kyoto, Japan.

We are thankful to NOAA, the ACE/MAG/SWICS teams and the SOHO/MDI team for solar and solar wind data. We also acknowledge the National Astronomical Observatory of Japan, Tokyo (NAOJ).

We acknowledge the IMP8/MAG and IMP8/MIT teams and the National Space Science Data Center (NSSDC).

Finally, we wish to express our gratitude to David Boteler and the other referee for their good and constructive comments that greatly helped us improve the paper.

Topical Editor M. Pinnock thanks D. Boteler and another anonymous referee for their help in evaluating this paper.

\section{References}

Amm, O. and Viljanen, A.: Ionospheric disturbance magnetic field continuation from the ground to the ionosphere using spherical elementary current systems, Earth Planets Space, 51, 431-440, 1999.

Bartels, J., Heck, N. H., and Johnston, H. F.: The three-hourrange index measuring geomagnetic activity, J. Geophys. Res., 44, 411-454, 1939.

Belov, A. V., Gaidash, S. P., Eroshenko, E. A., Lobkov, S. L., Pirjola, R., and Trichtchenko, L.: Effects of strong geomagnetic storms on Northern railways in Russia, Proceedings of the 7-th International Symposium on Electromagnetic Compatibility and Electromagnetic Ecology, Saint-Petersburg, Russia, 26-29 June 2007, 280-282, 2007.

Bolduc, L., Langlois, P., Boteler, D., and Pirjola, R.: A study of geoelectromagnetic disturbances in Quebec, 1. General results, IEEE T. Power Delivery, 13, 1251-1256, 1998.

Bolduc, L., Langlois, P., Boteler, D., and Pirjola, R.: A study of geoelectromagnetic disturbances in Quebec, 2. Detailed analysis of a large event, IEEE T. Power Delivery, 15, 272-278, 2000.

Bolduc, L.: GIC observations and studies in the Hydro-Québec power system, J. Atmos. Sol.-Terr. Phys., 64(16), 1793-1802, 2002.

Boteler, D. H., Pirjola, R. J., and Nevanlinna, H.: The effects of geomagnetic disturbances on electrical systems at the Earth's surface, Adv. Space Res., 22(1), 17-27, 1998.

Davis, T. N. and Sugiura, M.: Auroral electrojet activity index AE and its universal time variations, J. Geophys. Res., 71(3), 785$801,1966$.

Elovaara, J., Lindblad, P., Viljanen, A., Mäkinen, T., Pirjola, R., Larsson, S., and Kielén, B.: Geomagnetically induced currents in the Nordic power system and their effects on equipment, control, protection and operation, CIGRÉ General Session 1992, (CIGRÉ = International Conference on Large High Voltage Electric Systems), Paris, France, 31 August-5 September 1992, Paper No. 36-301, 10 pp., 1992.

Gleisner, H. and Watermann, J.: Solar energetic particle flux enhancement as an indicator of halo coronal mass ejection geoeffectiveness, Space Weather, 4, S06006, doi:10.1029/2006SW000220, 2006.

Gomez-Trevino, E.: Should the electric line be straight in magnetotelluric surveys?, Geophys. Prospect., 35, 920-923, 1987.

Gopalswamy, N., Yashiro, S., Liu, Y., Michalek, G., Vourlidas, A., Kaiser, M. L., and Howard, R. A.: Coronal mass ejections and other extreme characteristics of the 2003 October-
November solar eruptions, J. Geophys. Res., 110, A09S15, doi:10.1029/2004JA010958, 2005.

Kappenman, J. G. and Albertson, V. D.: Bracing for the geomagnetic storms, IEEE Spectrum, March 1990, 27-33, 1990.

Kappenman, J. G.: Geomagnetic storms and their impact on power systems, IEEE Power Engineering Review, May 1996, 5-8, 1996.

Kappenman, J. G.: An overview of the impulsive geomagnetic field disturbances and power grid impacts associated with the violent Sun-Earth connection events of 29-31 October 2003 and a comparative evaluation with other contemporary storms, Space Weather, 3, S08C01, doi:10.1029/2004SW000128, 2005.

Kappenman, J. G.: Great geomagnetic storms and extreme impulsive geomagnetic field disturbance events - An analysis of observational evidence including the great storm of May 1921, Adv. Space Res., 38, 188-199, 2006.

Kasinskii, V. V., Ptitsyna, N. G., Lyahov, N. N., Tyasto, M. I., Villoresi, G., and Lucci, L.: Effect of Geomagnetic Disturbances on the Operation of Railroad Automated Mechanisms and Telemechanics, Geomagn. Aeronomy, 47(5), 676-680, 2007.

Lam, H.-L., Boteler, D. H., and Trichtchenko, L.: Case studies of space weather events from their launching on the Sun to their impacts on power systems on the Earth, Ann. Geophys., 20, 10731079, 2002, http://www.ann-geophys.net/20/1073/2002/.

Lanzerotti, L. J., Thomson, D. J., and Maclennan, C. G.: Engineering issues in space weather, in Modern Radio Science 1999, edited by M. A. Stuchly, International Union of Radio Science (URSI), Oxford University Press, 25-50, 1999.

Lundstedt, H.: The sun, space weather and GIC effects in Sweden, Adv. Space Res., 37(6), 1182-1191, 2006.

Maurer, H. and Theile, B.: Parameters of the Auroral Electrojet From Magnetic Variations Along a Meridian, J. Geophys., 44, 415-426, 1978.

Mavromichalaki, H., Belehaki, A., and Serdari, V.: Structure of the July 1982 event in relation to the Magnetosphere's response, Astrophys. Space Sci., 180, 173-183, 1991.

Molinski, T. S.: Why utilities respect geomagnetically induced currents, J. Atmos. Sol.-Terr. Phy., 64(16), 1765-1778, 2002.

Pirjola, R.: On currents induced in power transmission systems during geomagnetic variations, IEEE T. Power Ap. Syst., PAS104(10), 2825-2830, 1985.

Ptitsyna, N. G., Tyasto, M. I., Kassinskii, V. V., Lyakhov, N. N., and Villoresi, G.: Do natural magnetic fields disturb railway telemetry?, Proceedings of the 7-th International Symposium on Electromagnetic Compatibility and Electromagnetic Ecology, SaintPetersburg, Russia, 26-29 June 2007, 288-290, 2007.

Ptitsyna, N. G., Kasinskii, V. V., Villoresi, G., Lyahov, N. N., Dorman, L. I., and Lucci, N.: Geomagnetic effects on mid-latitude railways: A statistical study of anomalies in the operation of signaling and train control equipment on the East-Siberian Railway, Adv. Space Res., 42(9), 1510-1514, 2008.

Pulkkinen, A., Lindahl, S., Viljanen, A., and Pirjola, R.: Geomagnetic storm of 29-31 October 2003: Geomagnetically induced currents and their relation to problems in the Swedish highvoltage power transmission system, Space Weather, 3, S08C03, doi:10.1029/2004SW000123, 2005.

Skoug, R. M., Gosling, J. T., Steinberg, J. T., McComas, D. J., Smith, C. W., Ness, N. F., Hu, Q., and Burlaga, L. F.: Extremely 
high speed solar wind: 29-30 October 2003, J. Geophys. Res., 109, A09102, doi:10.1029/2004JA010494, 2004.

Stüdemann, W. and Wilken, B.: Multispacecraft observations at the compressed magnetopause following the 13 July 1982 interplanetary shock, Planet. Space Sci., 34(9), 825-833, 1986.

Sugiura, M.: Hourly values of equatorial Dst for IGY, pp. 945948, in: Annals of the International Geophysical Year, vol. 35, Pergamon Press, Oxford, 1964.

Viljanen, A.: The relation between geomagnetic variations and their time derivatives and implications for estimation of induction risks, Geophys. Res. Lett., 24, 631-634, 1997.

Wallerius, A.: Solen gav Sverige en strömstöt (in Swedish), Ny Teknik - Teknisk Tidskrift, 29, 3, 1982.

Watermann, J.: The magnetic environment - GIC and other ground effects, in: Space Weather, Research Towards Applications in Europe, edited by: Lilensten, J., Springer, Chapter 5.0, 269-275, 2007.
Weaver, M., Murtaugh, W., Balch, C., Biesecker, D., Combs, L., Crown, M., Doggett, K., Kunches, J., Singer, H., and Zezula, D.: Halloween Space Weather Storms of 2003, NOAA Technical Memorandum OAR SEC-88, Department of Commerce, NOAA, Boulder, USA, 2004.

Wik, M., Viljanen, A., Pirjola, R., Pulkkinen, A., Wintoft, P., and Lundstedt, H.: Calculation of Geomagnetically Induced Currents in the $400 \mathrm{kV}$ Power System in Southern Sweden, Space Weather, 6, S07005, doi:10.1029/2007SW000343, 2008.

Zurbuchen, T. H., Gloeckler, G., Ipavich, F., Raines, J., Smith, C. W., and Fisk, L. A.: On the fast coronal mass ejections in October/November 2003: ACE-SWICS results, Geophys. Res. Lett., 31, L11805, doi:10.1029/2004GL019461, 2004. 